\title{
Annals of Surgical Oncology: The Global Journal for Surgeons Treating Patients with Cancer
}

\author{
Charles Balch, MD¹, Deborah Whippen², V. Suzanne Klimberg ${ }^{3}$, and Mark Roh, $\mathrm{MD}^{4}$ \\ ${ }^{1}$ Department of Surgery, John Hopkins Medical Center, Baltimore, MD; ${ }^{2}$ Editorial Office, Annals of Surgical Oncology, \\ Orange Park, FL; ${ }^{3}$ Department of Surgery, Division of Breast Surgical Oncology, University of Arkansas for Medical \\ Sciences, Little Rock, AR; ${ }^{4}$ Department of Surgery, MD Anderson Cancer Center Orlando, Orlando, FL
}

The Annals of Surgical Oncology is in its $17^{\text {th }}$ year of publication. As the journal has matured, it has become the most cited surgical oncology journal published and has been adopted as the venue for communicating new knowledge by surgeons all over the world. Manuscript submissions have increased by $65 \%$ between 2007 and 2009, the majority (70\%) of which now originate from outside the United States (Fig. 1). ${ }^{1}$ The Annals is also the primary resource for surgeons practicing in the United States, both in academic and community practice settings, because it is read by all members of the Society of Surgical Oncology (the majority of whom are in an academic practice) and the American Society of Breast Surgeons (the majority of whom are in a community-based practice). The Annals has also become an official journal with surgical and oncology societies in Europe, Latin America, and Africa. Thus, the readership and authorship constituency of the Annals of Surgical Oncology now reaches across the globe-both in print and electronicallyfor surgeons treating patients with cancer.

The scientific value of the journal is benchmarked with the Science Citation index. We are pleased to report that the journal's impact factor has increased almost 2 points to 4.13 , and the journal is now ranked 6th out of 166 surgery journals (Fig. 2, Table 1). This increase in impact is significant because it occurred despite an increased number of published pages from 2006 to 2007 (1753 vs 3637 printed pages), a variable that can push a journal's measured impact downward by expanding the denominator. Since the number of published pages remained stable over the past

(C) Society of Surgical Oncology 2010

Published Online: 21 July 2010

Annals Editorial Office

e-mail: info@asoeditorial.org
2 years, we are hopeful that the impact factor will continue to increase.

During 2009, articles published in the Annals of Surgical Oncology in 2007 and 2008 were cited in 3527 articles published in the literature. Given the growth of highquality papers published in the journal, the impressive volume of citations in recently published articles reflects the scholastic influence of Annals articles on the field of surgical oncology, both in the clinical and the research spheres.

The editorial leadership of the journal is also broadened to reflect the leadership of cancer surgeons not only in the United States, but also around the globe. The 2010-2011 Editorial Board roster, available online and in the front of this issue, displays the new and continuing Editorial Board members as well as two new subgroups-International Associate Editors and the Latin American Scientific Advisory Board. The addition of these international leaders to the journal reflects the increase visibility, usage, and citations of ASO worldwide.

We are also pleased to formally welcome Suzanne Klimberg, MD, to her new role as Deputy Editor of the journal; in this position, Suzanne is leading the journal as it becomes positioned to be an explicit educational resource for Maintenance of Certification. Dr. Eric Whitacre and colleagues have successfully piloted the Mastery of Breast Surgery, which is a case log system focused on three outcome measures specific to breast. This log qualifies for MOC Part IV and recently has been "linked" to the ASO to aid in obtaining credit for Part II. The SSO has appointed a committee to develop other venues for the surgical oncologist that includes Drs. Clifford Ko, Jeff Gershenwald, Doug Tyler, and Suzanne Klimberg. They hope to pilot a similar model for the American College of Surgeon Case $\log$ in five cancer areas with content specialist in each area. 


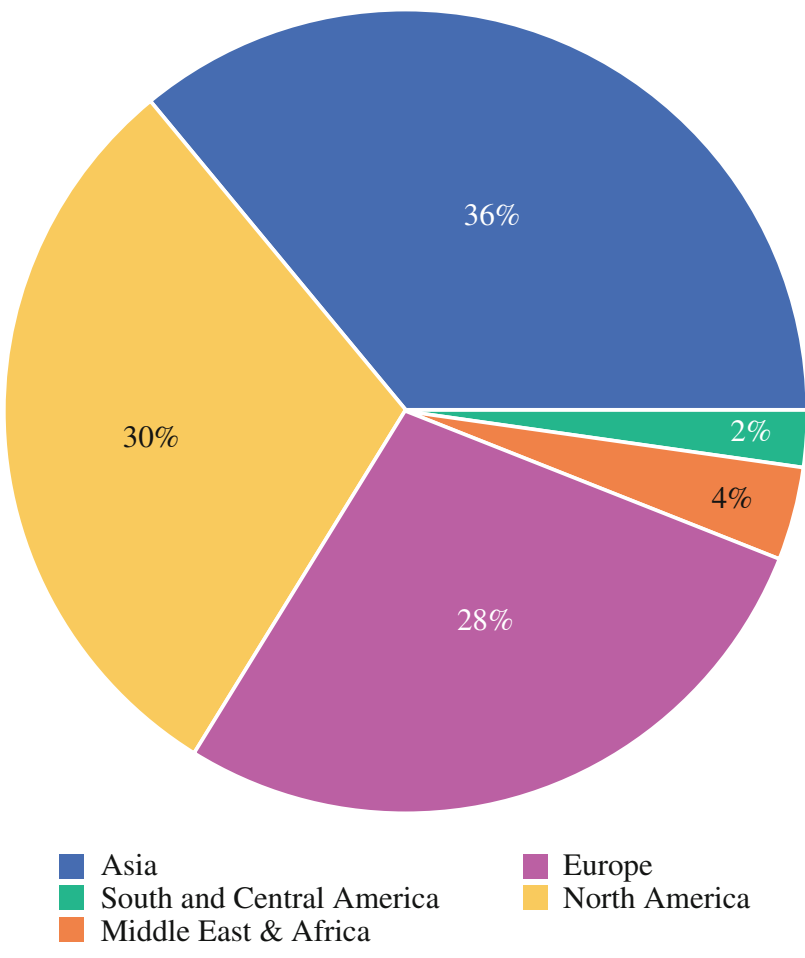

FIG. 1 Annals submissions by areas of the world

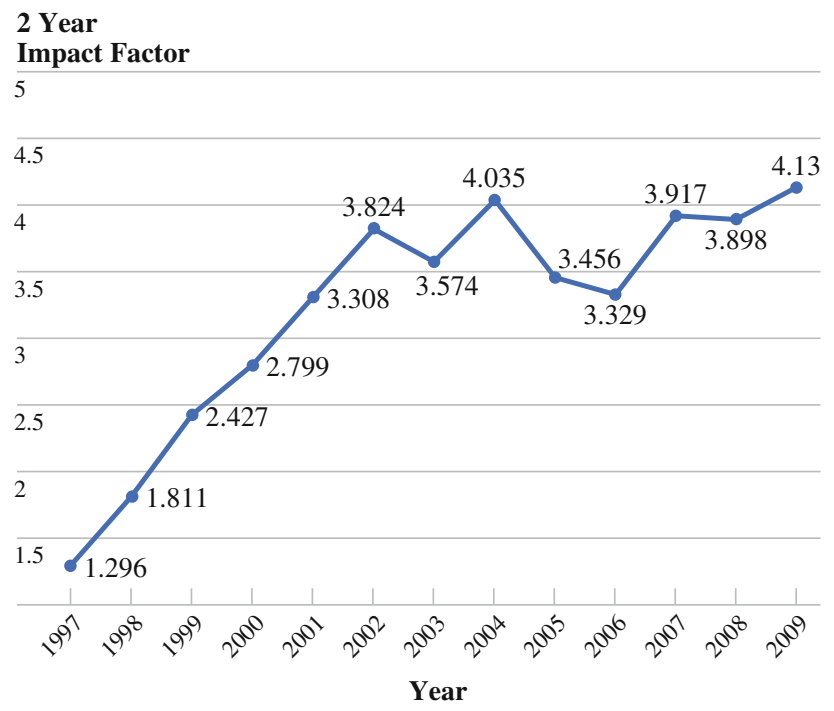

FIG. 2 Annals 2-year impact trend

Such a log would be likewise linked to the ASO as well as other to educational areas, in effect providing a venue for Part II and IV.

We are pleased to announce the forthcoming American Society of Breast Surgeons (ASBS) special issue. In October, the Annals will publish the first of an annual, dedicated issue devoted to ASBS articles that have been accepted by the peer review process of the Breast Section of the journal. Drs Sheldon Feldman and Funda MericBernstam are the Guest Editors for this 13th issue of the Annals, working in conjunction with Drs. Lisa Newman and Suzanne Klimberg. These articles have been peer reviewed with joint oversight by the ASBS and ASO leadership and reflect the very best of current research and education in the area of surgery and breast disease.

The Annals commitment is to address the readership and author needs of the entire community of surgical oncologists worldwide. This achievement of diversity and expertise is accomplished by recognizing the specific constituencies of U.S. academic surgeons and community practitioners, and international surgical oncologists and all surgical subspecialties. Increasing contributions to and participation in the journal from all these areas is evident. Manuscript submissions continue to climb, emanating largely from authors in Asia (36\%), North America (30\%), and Europe (28\%) (Fig. 1). The subject material covers all cancer types and surgical subspecialties (Table 2). The journal is grateful to these authors and readers of the journal-and also to the close to 2000 reviewers annually who donate their time to critically assess submitted papers. For articles completing manuscript review, which took 32 days on the average, and then forwarded to Springer in 2009, the average time between receipt at Springer and online publication was only 4.3 weeks!

How do readers access the journal and its content? Monthly print issues continue to be a valuable resource. Accessing the journal online, however, has become a primary channel for many. To position itself to be within easy and immediate reach, the journal is now available in three professional online areas: SpringerLink, the journal's publisher's website (full-text articles), the Annals of Surgical Oncology online portal (Fig. 3), and the Society of Surgical Oncology website. In addition, of course, all Annals content is indexed and available at PubMed in abstract form and accessible via search results on major search engine sites such as Google (Fig. 4).

The online activity of the journal in these areas is growing steadily, and many users move from one Annals access site to another as they use journal content in varying degrees of depth. The customized Annals portal was launched in September 2009. The home page allows for ease of use and improved navigation and searching of Annals content. The Annals portal is designed to be both a gateway to the journal full-text and to the SSO website and also to be an entry to in-depth specific information from and about the journal. You can quickly see the most recent and relevant research published in your field by searching Annals Online First content via article categories.

Significant enhancements are available on the Annals portal, including a dropdown box to search epub articles by subject category. The home page also features a list of the 
TABLE 1 Top 20 Journals in "Surgery" as sorted by the 2-year impact factor

\begin{tabular}{lll}
\hline Rank & Journal title & $\begin{array}{l}\text { 2-year impact } \\
\text { factor }\end{array}$ \\
\hline 1 & & 7.9 \\
2 & Annals of Surgery & 6.433 \\
3 & American Journal of Transplantation & 5.545 \\
4 & Endoscopy & 4.869 \\
5 & Journal of Neurology, Neurosurgery, and Psychiatry & 4.323 \\
6 & Archives of Surgery & 4.13 \\
7 & Annals of Surgical Oncology & 4.077 \\
8 & British Journal of Surgery & 4.062 \\
9 & American Journal of Surgical Pathology & 3.862 \\
10 & Surgery for Obesity and Related Diseases & 3.724 \\
11 & Liver Transplantation & 3.651 \\
12 & Journal of the American College of Surgeons & 3.644 \\
13 & Annals of Thoracic Surgery & 3.603 \\
14 & Surgery & 3.517 \\
15 & Journal of Vascular Surgery & 3.498 \\
16 & Transplantation & 3.427 \\
17 & Journal of Bone and Joint Surgery-American Volume & 3.307 \\
18 & Surgical Endoscopy & 3.254 \\
19 & Transplant International & 3.063 \\
20 & Journal of Thoracic and Cardiovascular Surgery & 2.934 \\
\hline & Obesity Surgery &
\end{tabular}

TABLE 2 Annals manuscript submissions by subject category

\begin{tabular}{lrcc}
\hline Subject category & 2007 & 2009 & $\%$ change \\
& No. & No. & 2007 to 2009 \\
\hline Bone and soft tissue sarcoma & 41 & 94 & +130 \\
Breast oncology & 283 & 316 & +12 \\
Endocrine tumors & 43 & 82 & +90 \\
Gastrointestinal oncology & 409 & 641 & +57 \\
Gynecologic oncology & 48 & 92 & +90 \\
Head and neck oncology & 41 & 79 & +91 \\
Healthcare policy and outcomes & 14 & 49 & +260 \\
Hepatobiliary and pancreatic tumors & 169 & 291 & +73 \\
Melanomas & 62 & 116 & +86 \\
Other/miscellaneous & 95 & 121 & +29 \\
Thoracic oncology & 36 & 93 & +160 \\
Translational research and biomarkers & 23 & & $>+500$
\end{tabular}

top 5 most viewed articles, a separate link for Multimedia Articles, and links to pertinent information on the Society of Surgical Oncology site. The newest feature of the home page is the "Annals Abstracts en Español," where selected Annals abstracts translated into Spanish will be available.

The SSO Website Committee has also spent considerable effort in the web redesign, which will include a dedicated Annals page featuring the list of the top five articles, the Online First articles, and all other issues. As a major strength of the new site, Annals articles will also be integrated with content from the entire site when searches are performed. Thus, Annals articles will appear side-byside with annual meeting presentations and other site content in search results. Author resources and submission links will also be featured. The new SSO site will launch later this year.

Last January, we published a "State of the Journal" which announced our partnership with the ASBS, outlined our new strategic plan, and delineated the new editorial sections. ${ }^{1}$ As Editors of the Annals of Surgical Oncology, 
FIG. 3 Annals of Surgical Oncology portal website: areas of reader interest indicated
FIG. 4 Primary web access sites to Annals content online

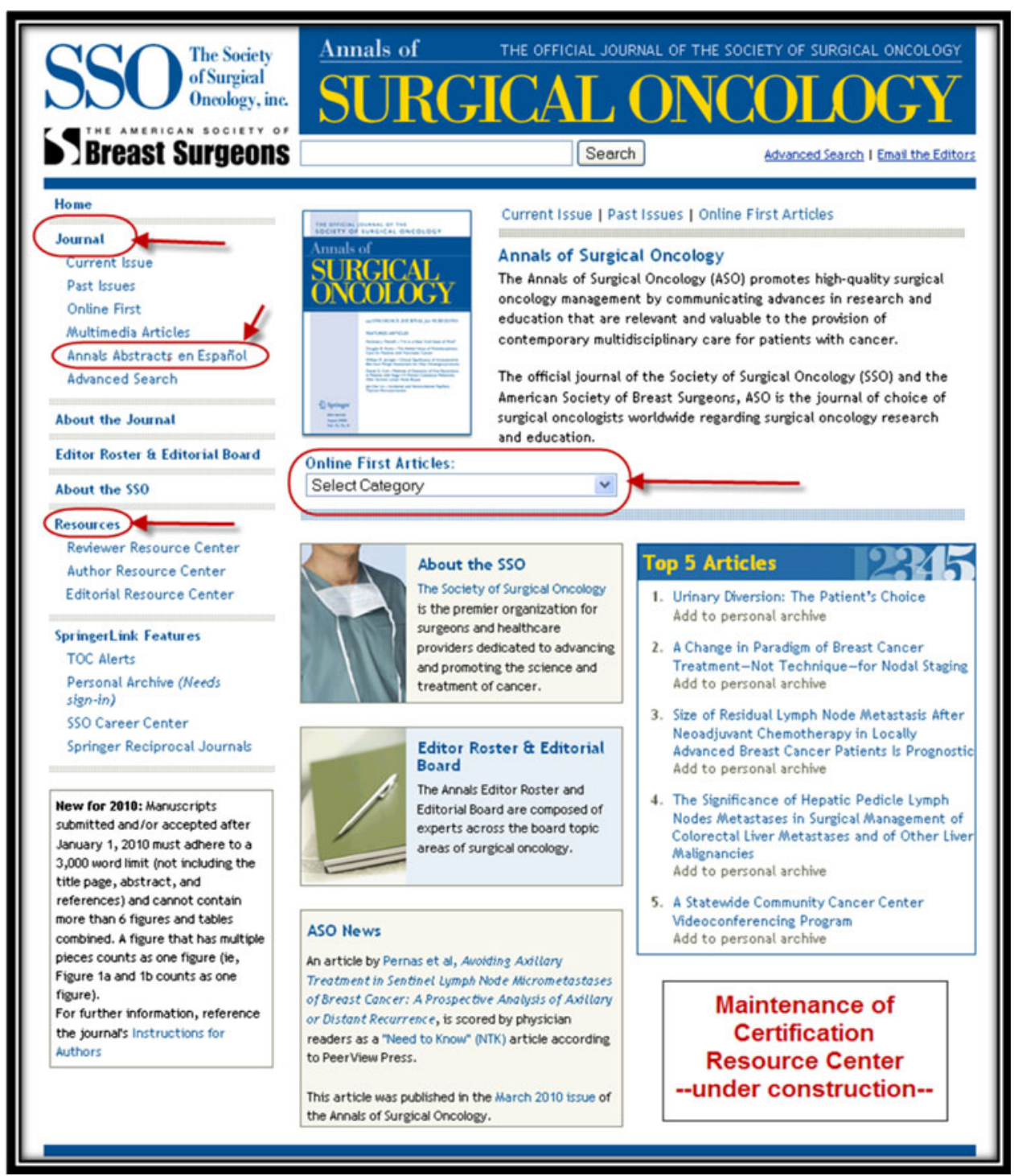

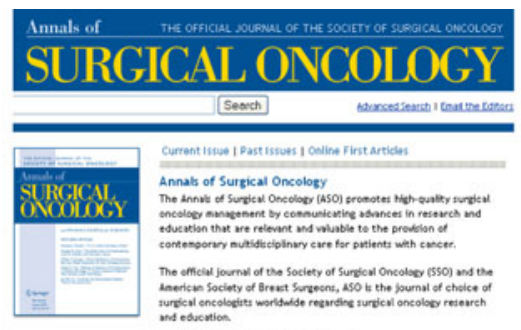

Annals Portal

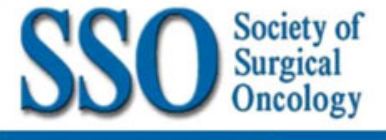

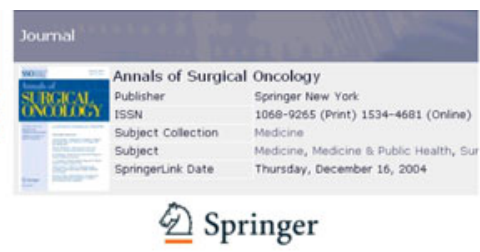

Full Text Articles

\section{₹ NCBI Resources $\square$ How To $\unrhd$}

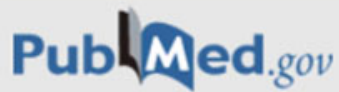

U.S. National Library of Medicine National Institutes of Health 
we are pleased to present this editorial report with new information about the journal's accomplishments and activities as we implement the Annals of Surgical Oncology's strategic plan to bring value to surgical oncologists worldwide.

\section{REFERENCE}

1. Roh MO, Whippen DA and Balch CM. State of the Journal 2010. Ann Surg Oncol. 2010;17:1-3. 